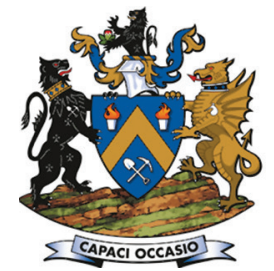

Affiliation:

1 School of Mines, China University of Mining and Technology, Jiangsu, China.

Correspondence to: A.J.S. Spearing

Email:

ajsspearing@yahoo.com

Dates:

Received: 7 Sep. 2020

Revised: 5 May 2021

Accepted: 7 Feb. 2021

Published: February 2021

\section{How to cite:}

Spearing, A.J.S., Zhang, J., and Ma, L. 2021

A new automated, safe, environmentally sustainable, and high extraction soft-rock underground mining method. Journal of the Southern African Institute of Mining and Metallurgy, vol. 121 , no. 2, pp. 89-96.

DOI ID:

http://dx.doi.org/10.17159/24119717/1370/2021

\title{
A new automated, safe, environmentally sustainable, and high extraction soft- rock underground mining method
}

\author{
A.J.S. Spearing1, J. Zhang1, and L. Ma1
}

\begin{abstract}
Synopsis
Ore deposits are becoming more complex to mine as a result of the exhaustion of surface and other easily mined deposits. There is also increasing socio-political pressure to design more environmentally sound, sustainable, and safe mining practices. Wang and Ma designed a mining method for coal, similar to a modified drift and fill using a continuous miner to take sequential cuts (rooms) that are subsequently backfilled. The authors have modified the concept to make it more autonomous, safer, and less costly using highwall coal mining techniques, modified and adapted for underground applications. The method is more flexible than longwall mining and the percentage extraction would seem to be in the same range. In addition because of the backfilling, surface subsidence would not be a major issue and could be more effectively managed.
\end{abstract}

\section{Keywords}

highwall mining, underground coal mining, backfilling, backfill face stability, continuous miner, safety.

\section{Introduction}

Longwall mining is currently the safest and most effective method for soft rock deposits, especially coal. Unlike room and pillar, which has a typical extraction range of 40-60\% depending mainly on depth and seam height, longwall mining has typically around $80 \%$ extraction and is also used for deep coal deposits (>1000 m). Room and pillar mining tends to become less suitable as depth increases as the economics of the lower extraction becomes a major issue. One of the main problems associated with longwall mining has been surface subsidence. If there is nothing sensitive on surface above the longwall, rehabilitation can take place after mining and is relatively simple, cheap, and effective. Conventional longwall mining below sensitive infrastructure such as water, rail, major roads, and highrise buildings has been restricted in the past, but advances in effective backfill techniques, mainly solid backfill mining (Zhang, Miao, and Guo, 2009; Zhang, Zhou, and Huang, 2012) have now resolved the subsidence issue. Clearly this involves a cost increase, but many of these coal deposits would not be mineable otherwise.

\section{Conventional highwall mining}

Highwall mining using augers originated in the USA in the 1940s (Volkwein, Mucho, and Bhatt, 1995). According to Zipf (2005), about 60 highwall mining systems and about 150 auger systems were active in the USA in 2005, producing about $45 \mathrm{Mt}$ of coal annually. Initially, the systems used a large auger drill to produce the coal but a customized continuous miner (CM) was found to be more efficient and productive.

On surface a web (slender pillar) is left between each drift (slice) mined. Backfill is not used due to the cost and backfill access issues (only from one side which makes it very difficult in practice).

The Continuous Highway Miner (CHM) can currently mine unsupported drifts (slices) up to $500 \mathrm{~m}$ (Figures 1 and 2).

The CM is moved forward using Addcars or similar; the principle is the same as for a drill bit with drill rods. The coal is transferred from the Addcars into a transfer box and onto a conveyor belt.

The CM can be fitted with a gamma ray device to ensure it mines on the seam and does not cut waste in the roof and floor (Figure 3).

The Addcars (Figure 4) are the key components and are added automatically as the CM moves forward cutting the coal. The Archimedes screws in the Addcars convey the coal out to the surface. Once the drift is completed to the design length, the machine automatically pulls them out and removes the Addcars one at a time and stacks them, so that the CM can be recovered and the next slice mined. Some Addcars now use an internal conveying system in place of the augers. 


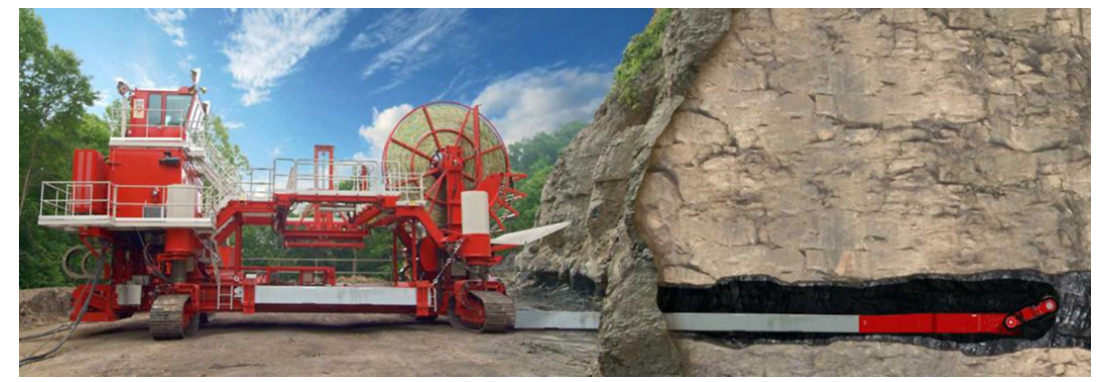

Figure 1-The highwall coal mining concept (Caterpillar, 2014)

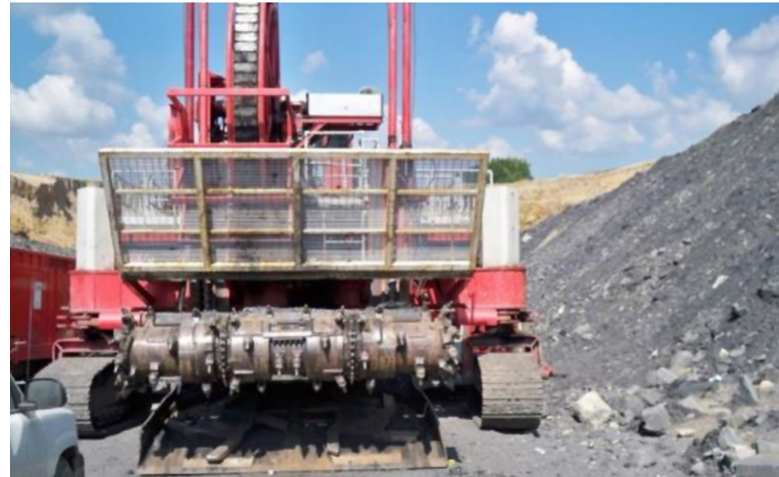

Figure 2-The continuous miner used for highwall mining

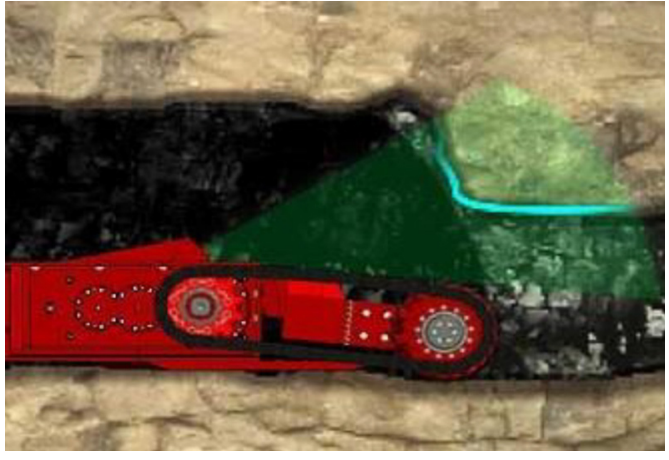

Figure 3-The gamma ray instrument fixed to the continuous miner (Caterpillar, 2014)

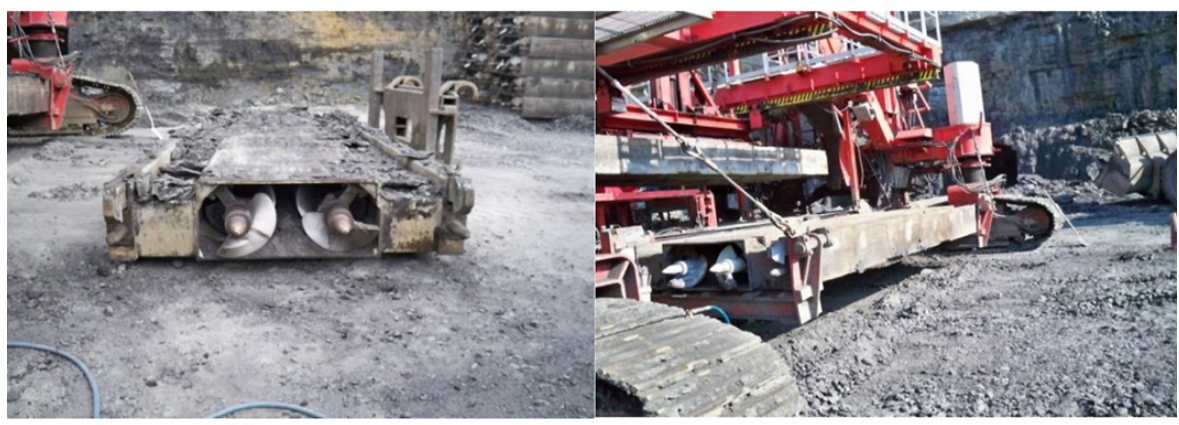

(a)

(b)

Figure 4-(a) An Addcar with the screw to move the coal, (b) The automatic unit for adding or removing the Addcar units

The highwall miner referred to was used over a period of several years at Knight Hawk Coal LLC in the Illinois Basin. The coal seam height varied from 2.00 to $2.15 \mathrm{~m}$. The $\mathrm{CM}$ cutter head was $3.5 \mathrm{~m}$ wide and $10.2 \mathrm{~m}$ long. The Addcars with the screws were $6.2 \mathrm{~m}$ long and where able to handle all the coal produced by the CM. The maximum production rate was $260 \mathrm{t} / \mathrm{h}$, and the highest monthly production was over $62000 \mathrm{t}$, running 32 shifts of 10 hours each (Smith, 2020).

These results clearly show the potential of the highwall mining equipment with the screw auger Addcars.

Trials with highwall mining in Australia found little application and punch longwalls were preferred instead (Mo et al., 2016). At South Blackwater Mine in 2000 (ACARP, 2000) highwall mining equipment was used to develop punch longwall gates. The procedure was first to cut a $3.5 \mathrm{~m}$ wide entry and then increase it to the final width of $5.2 \mathrm{~m}$ in a second pass. Even though rockfalls were an issue during the first operation (the rock was very weak) the test was considered a success. The second operation was not undertaken because the immediate roof was found to have an unconfined compressive strength of 3 to
$10 \mathrm{MPa}$, which the ACARP investigators Shen et al., 2000) noted is the weakest in the Australian coal industry based on the CSIRO database.

Subsequently, an underground trial (Buddery and Hill, 2004) was planned for Southern Colliery in Australia. The coal seam was $2.7 \mathrm{~m}$ high and an auger (not a $\mathrm{CM}$ ) with a diameter of $1.6 \mathrm{~m}$ was used. Thin rib pillars (webs) were planned at a minimum of $0.9 \mathrm{~m}$ and no backfill was sconsidered. Auger holes were typically $60 \mathrm{~m}$ long, but up to $100 \mathrm{~m}$ was achieved. The span between 'auger panels' was limited to $105 \mathrm{~m}$. The work was not continued and underground highwall mining applications were considered only for small areas where longwalling was not feasible. This was because the layout yielded poor extraction and the design principles used were too conservative.

The highwall system is, however, well proven and established in the USA and continues to be used successfully.

\section{Development of highwall technology for underground}

The method outlined in this concept paper is thought to resolve some of the previously considered problems and constraints, not 
only with highwall mining but also some issues associated with room and pillar mining as well as longwall mining. It follows the work on a method called Continuous Extraction and Continuous Backfill, developed by Ma and co-workers (Ma et al., 2019; Yu, Ma, and Zhang, 2020).

Room and pillar mining is limited as regards depth, and also suffers from poor extraction generally. Longwall mining is highly productive but cannot be used if the roof is not cavable or in geological disturbed coal seams. Faults and folds with vertical displacements of more than 1 to $2 \mathrm{~m}$ are very difficult to mine through effectively with a longwall panel. A modified highwall mining method, preferably using backfill, is therefore proposed, and should be viable at depth and be better able to mine around or through adverse geology.

An Australian start-up has recognized the potential for using highwall mining technology underground and is progressing with the concept (PBE Technologies, 2017). Figure 5 shows the conceptual layout. The method outlined in this paper has several potential and important differences and advantages, including the following:

> In the preferred option, no pillars are left between successive cuts. This has productivity and extraction advantages - pillars can be undesirable as they become stress concentrators, which can lead to falls of ground and even violent failure. This potential problem can be exacerbated by guidance issues when cutting results in smaller pillars, or in weaker rock mass areas.

> Addcars with screws are used rather than flexible conveyors, which have many more moving parts and could therefore be less reliable. Remote maintenance is impossible on conveyors.

> The method outlined in this paper is much less capital intensive.

- An external ram inserts and retracts the Addcars, and therefore there is no self-propelling equipment in the remote and unsupported slices.
> The backfilling system maximizes extraction while protecting the surface from subsidence. This has been proven on many coal mines in China.

The system using the flexible bridge conveyor train will have a higher instantaneous hourly tonnage capacity when it is available (i.e. operating). The main problem, however, is that flexible conveyors have many moving parts and systems and they cannot be readily accessed if maintenance is needed as the cuts will be unsupported. Such a system has been designed, however, and is undergoing trials. The two systems will obviously be compared, and economics will be the main determining factor.

The key to the success of the remote operation is mining at a stable short-term unsupported span. There is a considerable knowledge base from conventional surface highwall operations and some of the calibrated modelling for deeper underground conditions (Ma et al., 2019; Yu, Ma, and Zhang, 2020).

The potential for such systems has already been established in trials of the continuous extraction continuous backfill method (CECB) developed by Ma and co-workers (Ma et al., 2019; Yu, $\mathrm{Ma}$, and Zhang, 2020). This method is similar to the PBE method but has already been extensively tested in the Ordos, Jincheng, Xinwen, and Zaozhuang coal mining areas of China. To date 2.6 Mt of coal have been extracted using CECB. These systems have used shuttle cars or continuous conveyor to move the coal out of the cuts (slots). Daily tonnages from a single system regularly average $4500 \mathrm{t}$ at a reported capital outlay of about $8 \%$ of an equivalent longwall operation.

\section{Mining method outline - safe highwall underground remote mining (SHURM)}

The following method is a possible alternative to room and pillar coal mining (with stooping - secondary pillar recovery), and for coal seams (or parts of coal seams) that perhaps are of a size or condition not readily suitable for longwall mining. It may even be less costly than some longwall mines, based on results to date (Yu, Ma, and Zhang, 2020). The main difference between

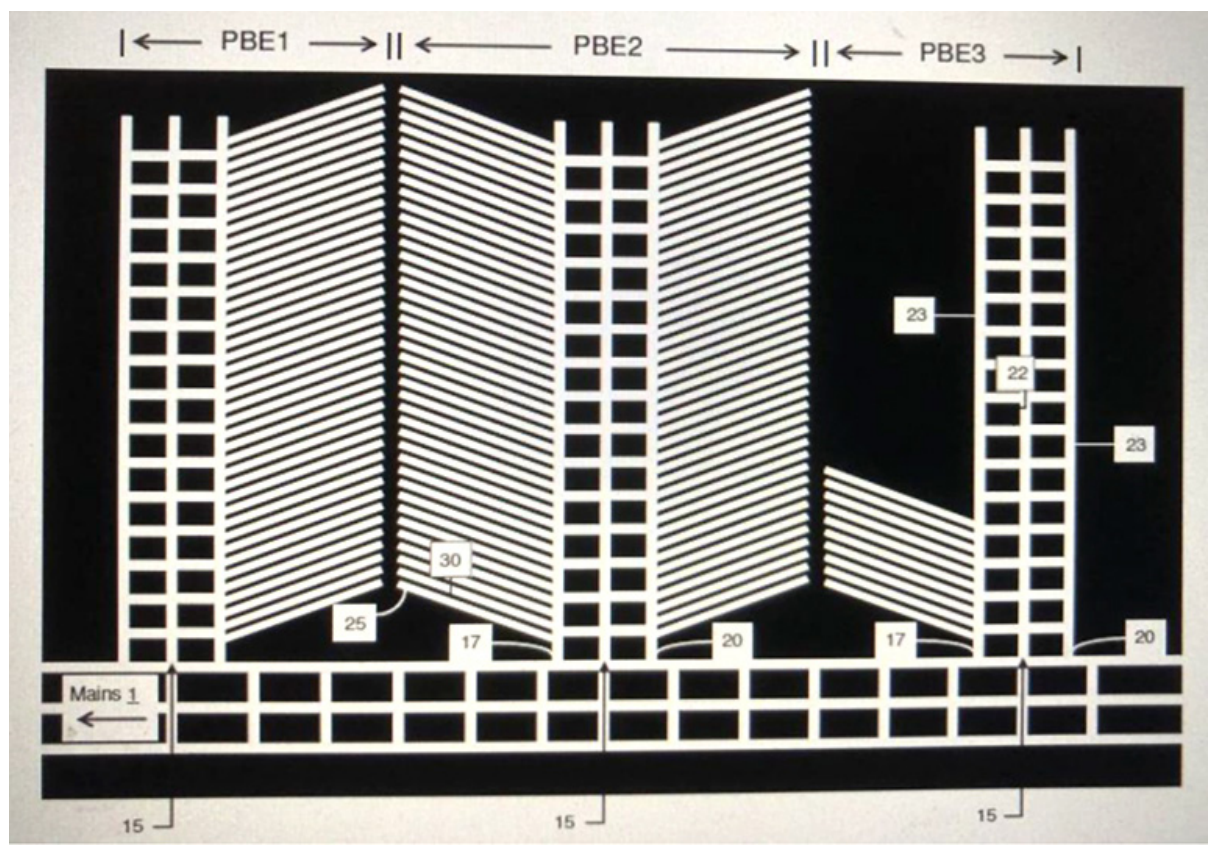

Figure 5-The conceptual highwall mining design (PBE Technologies, 2017) 
SHURM and CECB is the use of more reliable and less costly screw auger Addcars and the fact that the cuts are unsupported. CECB trials are also planned using smaller unsupported cuts so that all mining method options can be compared for a particular coal deposit. Local geology, hydrology, surface infrastructure, and seam height are the main considerations.

The SHURM method is based on conventional highwall mining. It is modified for underground use, preferably with backfill (to maximize extraction and eliminate surface problems). With backfilling it is likely that the percentage extraction will be greater than with conventional longwalling without backfilling, because the backfill becomes significantly load-bearing considerable faster than conventional gob. An alternative to backfilling would involve leaving a slender pillar (web) between the cuts (slots), as is common practice with conventional highwall mining. A hybrid of slender web pillars and uncemented backfill could also be considered. It is expected that SHURM could be used for coal seams over $1.8 \mathrm{~m}$ high. An example of a layout is shown in Figure 6.
Currently, an unsupported stable span of about $4 \mathrm{~m}$ is assumed. This could be reduced for a weaker coal seam roof to, say, a minimum of $3 \mathrm{~m}$ if needed. The CM and Addcar size would just need to be reduced accordingly. The start of the panel is shown in Figure 7.

In the method, the slots are preferably holed through between the drifts so that no internal pillars are left that could potentially fail. Slots would be left incomplete only if dictated by local geological conditions and seam properties.

Addcars with augers (screws) are preferred to conveyors because they have fewer moving parts (only bearing sets) that need maintenance and which could potentially fail in the unmanned and unsupported slot. The flexible conveyor units have far more moving parts and this would adversely affect system availability. Addcars with augers are simple and reliable and have proved to be successful and able to handle the coal tonnage produced by the CM (Caterpillar, 2014)

Ideally, mining would be conducted updip to facilitate water drainage and make backfilling easier and less costly. The

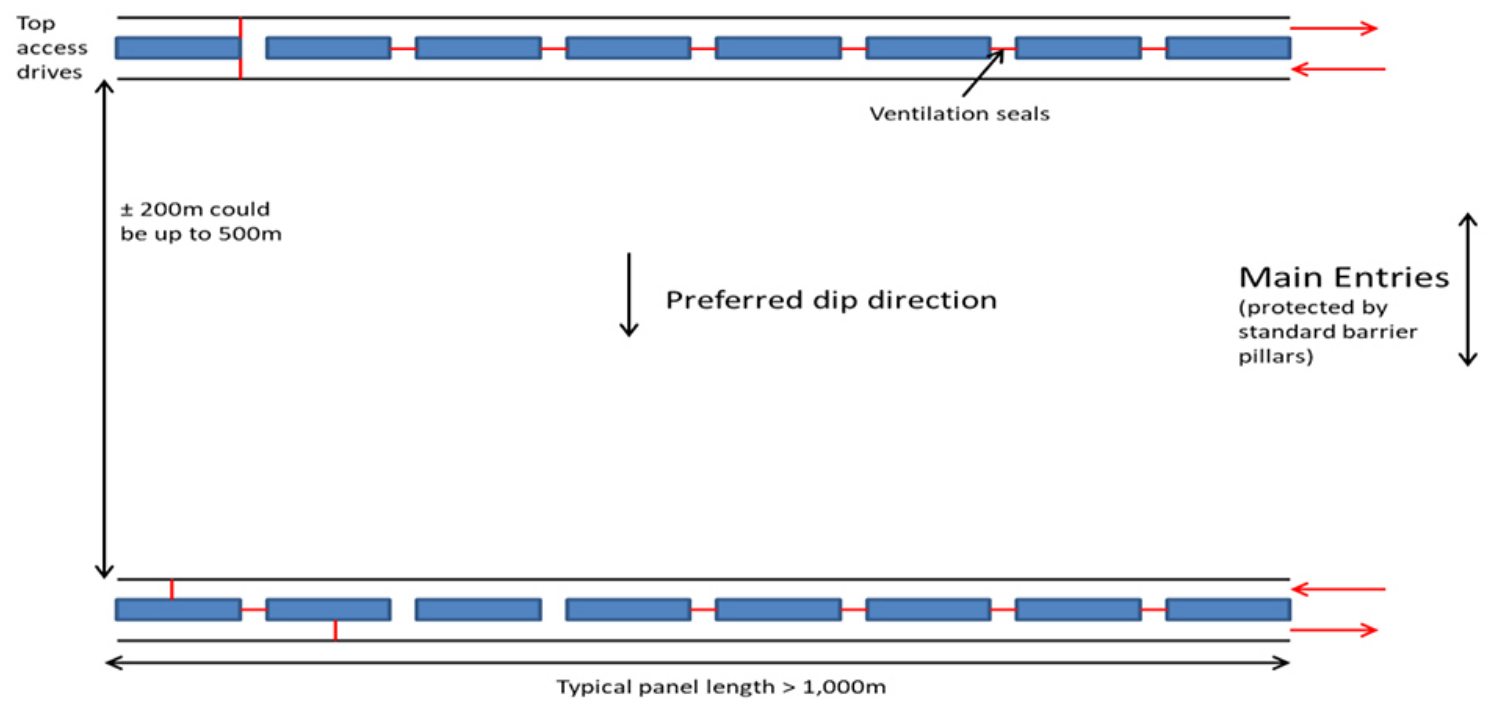

Figure 6-An example of a panel layout

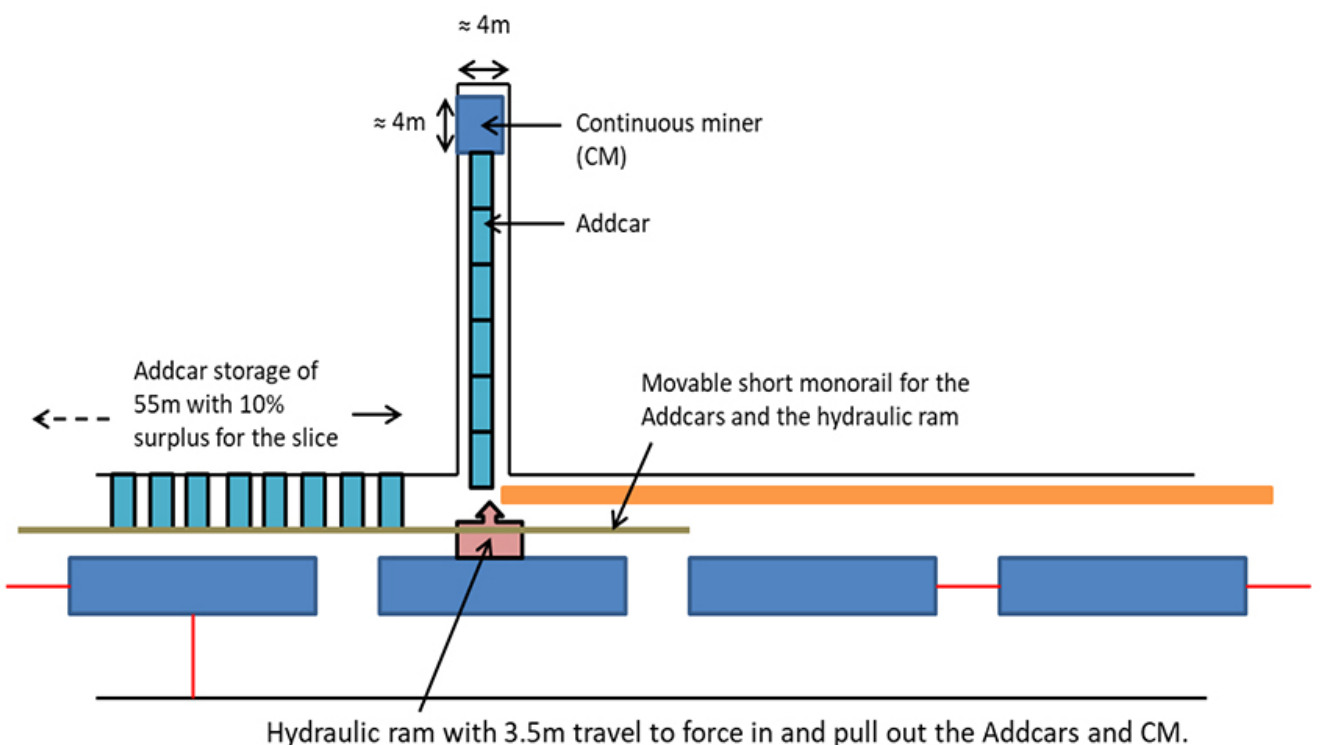

It exerts pressure from the pillar and between the floor and roof to provide the thrust.

Figure 7-The start of a new SHURM panel 
backfilling would preferably be done downdip to improve roof contact. The system for underground would obviously need to be much more compact than that for surface operations.

As mining progresses towards the main entries, the monorail sections could be removed and reinstalled in front of the retreating overall panel face (towards the main entries) as successive slices are mined.

\section{Assumptions for a safe highwall underground remote mining (SHURM) mine section}

Highwall miners currently produce from 40 to $120 \mathrm{kt} /$ month (Mo et al., 2016). For this prefeasibility example a conservative production rate of $50 \mathrm{k} \mathrm{t} / \mathrm{month}$ is assumed. Continuous highwall miners (CHMs) can mine up to $500 \mathrm{~m}$ but, again, to be conservative, a length of $200 \mathrm{~m}$ has been used in this prefeasibility study.

A single cut (or slice) would be $200 \mathrm{~m}$ long, $4 \mathrm{~m}$ wide, and (say) $2.5 \mathrm{~m}$ high. Assuming an in-situ coal density of 1.3, each cut would yield $2600 \mathrm{t}$. Based on the assumed annual production, a single SHURM unit would cut 20 slots per month, and produce $600 \mathrm{kt}$ annually. A typical mine could therefore consist of several SHURM units, which would give it considerable flexibility.

For a $200 \mathrm{~m}$ long extraction panel, 50 Addcars would be needed so 60 is assumed for extra capacity to allow for maintenance. For safety considerations the Addcars would only be stacked four high (i.e. 15 stacks of four each). Assuming the Addcars to be $2.5 \mathrm{~m}$ wide and stacked $1 \mathrm{~m}$ apart, a storage length of about $55 \mathrm{~m}$ is needed. The monorail Addcar transport system (for installing or removing Addcars) would be fully automated.

The width of the access drives would be limited to (say) 6-8 m depending on local strata conditions. Space is obviously a constraint, so the hydraulic ram in Figure 7 would need to be about $2.5 \mathrm{~m}$ wide and be able to push and pull the Addcars in and out of the slot quickly and efficiently.

We assume therefore that the ram width is kept to about $2.2 \mathrm{~m}$ maximum (when the hydraulic cylinders are fully retracted). The exact required capacity of the ram is unknown at this stage, but based on surface highwalls, the minimum forward thrust should be at least $135 \mathrm{t}$, and $275 \mathrm{t}$ to retract (Caterpillar, 2014). A suitable factor of safety would be built-in. This device would therefore need a three-stage telescopic cylinder with a total extension of $4.5 \mathrm{~m}$ (longer than an Addcar). This would give a first extension cylinder of $1.7 \mathrm{~m}$, a second of $1.5 \mathrm{~m}$, and a third of $1.3 \mathrm{~m}$, for a total of $4.5 \mathrm{~m}$. The stabilizers for the ram would need to carefully designed and tested and have a large contact area with the floor and the roof (and possibly with the rib too) in order to remain stable during the pushing (cutting) and retracting of the Addcars after a slice has been mined.

To move the ram unit after each slice is mined, it could be mounted on a sled and dragged to the new slice position or be crawler-mounted and move itself. It would be secured for each cut using hydraulic rams between the roof and floor, and possibly against the ribs.

If methane build-up in the slices/slots is an issue, a compressed air line, modularized ventilation duct, or similar could be incorporated on the $\mathrm{CM}$ and along the Addcars to dilute any gas. This would limit the chance of a frictional ignition caused by one of the CM picks sparking off a hard rock. In November 1991 in Kentucky, USA a fatality occurred, apparently cause by a highwall CM ignition (Volkwein, Mucho, and Bhatt, 1995).

\section{Backfilling}

\section{Backfill requirements}

Backfilling is a key to the success of SHURM for the following reasons.

> It drastically reduces surface subsidence and helps protect the overlying water table.

> It increases the percentage extraction as it reduces the stresses carried by the pillars.

> It moves waste products from surface to underground, thus improving the environment.

The backfill would need to be free-standing as the CM will need to mine alongside it. It would therefore need a cementitious component. Backfilling, and the time before mining can resume next to a backfilled slice (so the strength needed to free stand could be developed), is a potential bottleneck that needs to be designed out.

Blight and Spearing (1996) showed that for backfill to free stand at a certain height the following minimum cohesion is needed:

$>2 \mathrm{~m}$ height, minimum cohesion about $7 \mathrm{kPa}$

$>3 \mathrm{~m}$ height, minimum cohesion about $10 \mathrm{kPa}$.

These figures can be used for initial backfill strength development tests as a guideline.

A major instrumented retaining structure will need to be constructed on the bottom entry level in the slice just mined, and a minor one on the top entry, so that personnel can still work during backfilling in the downdip entries.

The fill volume per slice is $2000 \mathrm{~m}^{3}$. Assuming, for downstream safety considerations that an initial fill rate of $50 \mathrm{~m}^{3} / \mathrm{h}$ is used for the first 5 hours, then $100 \mathrm{~m}^{3} / \mathrm{h}$ afterwards, fill time would be about a day (including a couple of hours to erect the backfill barricades). A slot would be mined on average every 1.5 days, then take a day to backfill.

Many cut sequences are possible using a staggered extraction. In the example in Figure 7 the backfill would need 3 to 4 days to gain adequate strength before it is mined against (based on the cohesive strength developed). If this is insufficient, the extraction sequence could be readily modified.

Backfill placement will be important as the backfill must be in good contact with the roof over the whole length of the slice. Mining updip and backfilling downdip would greatly assist with this, especially if the dip exceeds $3^{\circ}$.

Clearly, the backfill is the area requiring the most innovative design so it does not become an insurmountable bottleneck. The production plan can be adjusted to resolve this, it is believed at this early pre-feasibility stage.

It would seem that slurry or paste backfilling would be cheaper and easier, especially if the coal seam had a shallow sdip. Tight safety-related systems and controls would be needed as the production focus would be downdip of the backfilling (in the bottom access entry) and filling would be from the top access entry.

\section{Backfilling options}

To develop free-standing ability quickly a suitable cement and/or pozzolan (such as fly ash) will be needed.

The cementing options are basically as follows.

$>$ Portland cement

- This is generally effective but costly. It is estimated 


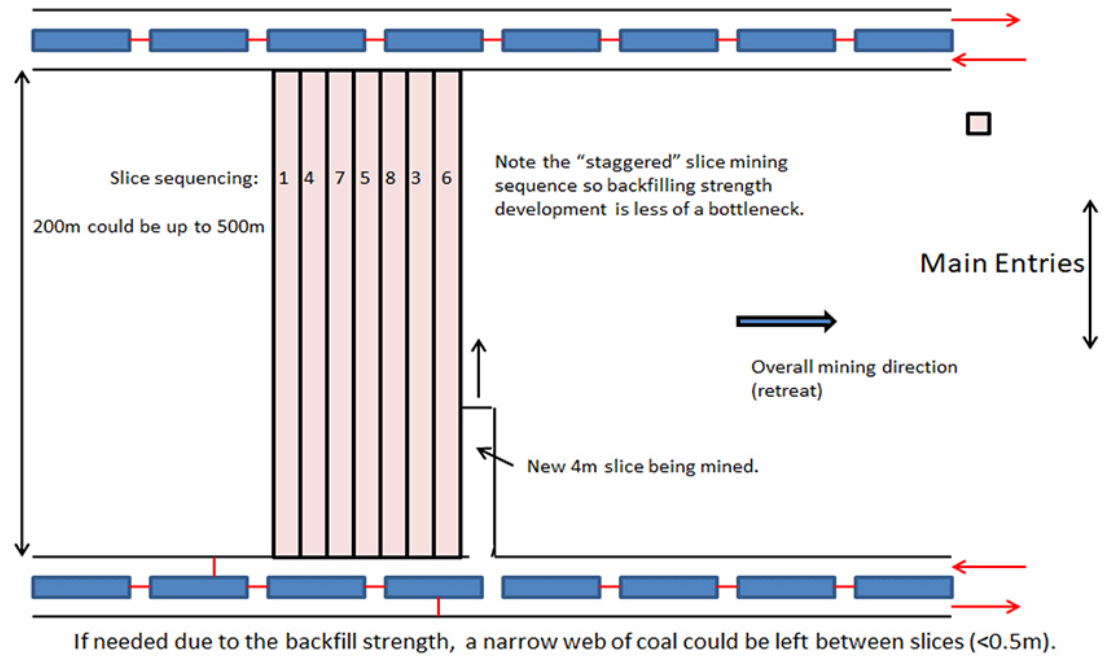

Figure 8-An example of a staggered slice/slot layout to give time for the backfill to develop adequate strengt

that at least a $4 \%$ by weight addition would be needed to make the early strength gain of the backfill fast enough, based on previous experience.

Activated fly ash (with lime)

- This system is viable but the strength gain tends to be relatively slow.

- Activated (quenched and finely ground) blast furnace slag

- This is a really cost-effective pozzolan, produced routinely in South Africa (Afrisam, n.d.), and with all of China's iron ore blast furnaces this is good option in that country. For backfill in South Africa, the $5 \%$ cement addition was replaced with $5 \%$ ground granulated slag activated with slaked lime, and it achieved faster strength development at a much smaller material cost.

> Silicated backfill (ettringite, which is a complex molecule with 32 molecules of water as the hydration product). This was developed by Minova (Smart, Spearing, and Harrison, 1993). A 4\% addition reduces runoff water in a slurry from about $44 \%$ to less than $10 \%$, and in a high-density slurry it virtually eliminates the water runoff and post-filling shrinkage.

> Other polymer-based products that can gain strength and undergo minimum shrinkage.

The backfill must not shrink after placement as this could create serious problems such as:

> Poor contact with the roof

- The need for an additional cementitious addition, because this component tends to be the finest in the backfill and so comes out with the post-filling drainage water.

Backfill strength development tests must be carried out to determine the rate of strength gain and cost, in order to formulate the optimum backfill. A key consideration will be the need to limit post-filling shrinkage, and based on previous experience this points to the silicate backfill system (Smart, Spearing, and Harrison, 1993).

\section{Backfill placement}

If the coal seam is relatively flat $\left(\operatorname{dip}<3^{\circ}\right)$, a sacrificial PVC or HDPE barrier will probably be needed in the slice to ensure tight backfill to the roof. This has been done routinely in China

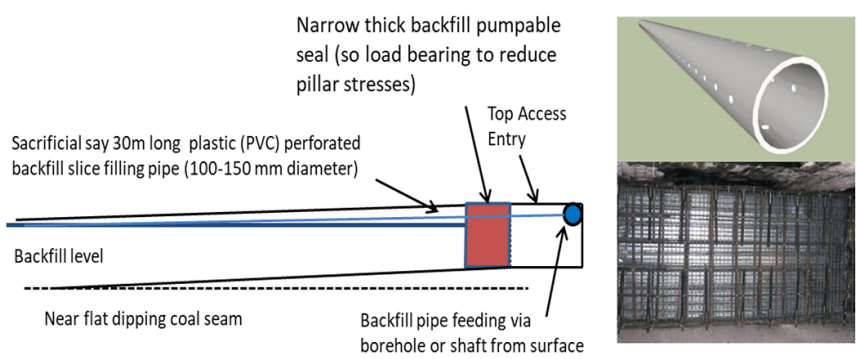

Figure 9-Possible backfilling method using sacrificial plastic pipes and a barricade that could be simplified (after Strata Worldwide)

with CECB and was successfully applied on the gold mines in South Africa, but for a different application and at stoping widths (mining heights) of typically 1 to $2 \mathrm{~m}$. The pressure in the delivery system ensures tight roof contact. A possible method is shown in Figure 9.

\section{Potential advantages of SHURM}

This method has many potential advantages over other conventional coal mining methods. Clearly a detailed cost comparison is needed so that the mining methods can be quantitatively compared. The following advantages are anticipated.

\section{Compared to room and pillar mining}

> Much higher coal seam extraction, especially as depth increases.

$>$ Not depth-limited

> Support costs are much lower

- Safety would be improved, as less labour is needed and no personnel work at the advancing face

> Ventilation is easier and better controlled (due to the backfill sealing off all old areas)

> Higher productivity is possible because the operation of the $\mathrm{CM}$ is not interrupted for rockbolt installation in the production slots. Production is also semi-continuous and does not need to wait for scoop trams or ram cars to collect and move the coal to the panel loader and conveyor belt. The use of flexible conveyors can resolve this productivity issue in room and pillar mines, but it is still not commonly used due to cost and reliability issues. 


\section{Compared to room and pillar with stooping (secondary pillar extraction)}

$>$ Significantly improved safety

$>$ Lower support costs

Much higher. productivity

> Coal seam extraction should be higher.

\section{Compared to longwall mining (without backfilling)}

> Selective areas can be left unmined; because of adverse geology, poor coal quality, water, or local instability' for example

> Surface subsidence and groundwater interruption are greatly reduced (or eliminated) if backfill is used

> Less capital-intensive

- The same or slightly higher percentage extraction

- Safer, as no labour is required on the producing face.

> More geologically disturbed coal seams can be mined efficiently. Short or narrow longwalls are not very costeffective.

The main disadvantage may be higher production cost, due mainly to the backfilling, and this would need to be investigated on a site-by-site basis. Clearly, several SHURM sections would be needed to match the tonnage output from a longwall.

The pillars on the top and bottom entries of a SHURM panel would be less stressed than in conventional longwalling without backfilling, because of the high early-strength backfilling. They are used for two panels (as in longwalling) - as a top entry first and then as the bottom (main) entry second. A typical panel layout is shown in Figure 10.

\section{SHURM variations}

The method is very flexible, and hybrid methods can also be considered:

> A thin, (say) $0.5 \mathrm{~m}$ web, could be left routinely or for localized areas where strata conditions have deteriorated. If

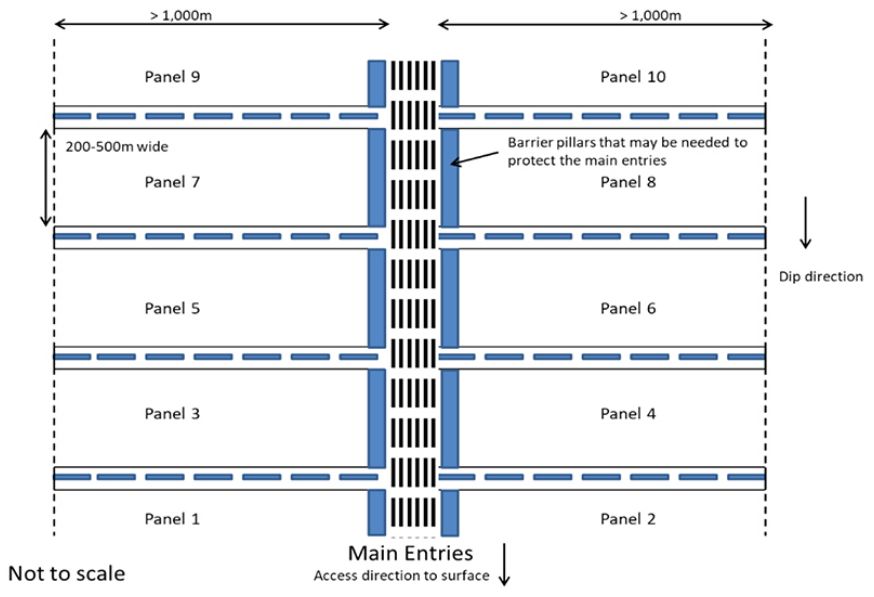

Figure 10-A panel layout for SHURM webs are left, uncemented, cheap backfilling could be used or even no backfill at all, but a conservative design would be needed to avoid pillar runs and/or surface subsidence. The SHURMS standard method should have about an 85 to 95\% in-panel extraction, depending on the panel length. If the webs were routinely left, this would drop to between 76 and $85 \%$, which is still a much higher extraction than room and pillar mining. This assumes a two-entry system with a $12 \mathrm{~m}$ wide chain pillar, and is obviously dependent on the mining height and panel width.

- Web pillars could be left if local conditions deteriorate or burnt coal is encountered for example, if cemented backfill was used in a standard SHURM layout.

\section{Main challenges}

The main challenges that need to be addressed are as follows:

> The safe unsupported span under various coal seam and immediate roof conditions. A minimum of $3 \mathrm{~m}$ will probably be needed for SHURMS to be an effective method.

> The highwall mining equipment suite needs to be made much more compact to fit into the underground entries. This has already been achieved for the CM to a certain extent, and reducing the length of the Addcars from the current length of $6.2 \mathrm{~m}$ to 3.5 to $4.0 \mathrm{~m}$ will not be an issue.

> The monorail that adds and reclaims Addcars needs to operate safely, remotely, and quickly, and the handling attachment will need to be effective.

> The hydraulic cylinder unit for advancing the $\mathrm{CM}$ and Addcar string, then reclaiming the Addcars, needs to be mobile (track-mounted, perhaps) and be able to lock itself into position in order the move the Addcar train in and out of the slot. It would need to hold itself it position with hydraulic cylinders between the roof and floor (similar to a longwall shield, possibly with a canopy for safety and to spread the support load).

- A small transfer box will be needed to transport the coal from the Addcars to the flexible conveyor train or equivalent in the entry drifts.

> The rapid, high early-strength development of the backfill. The cost is the main issue as, technically, any strength can be obtained but at a cost (too high a cementitious addition). The technical challenge is depicted in Figure 11.

\section{Conclusions}

Based on this conceptual study, the following conclusions can be drawn.

(1) The SHURM concept appears to have potential and no potential fatal flaws have been identified so far.

(2) A conceptual feasibility study is needed to compare SHURM, room and pillar, and longwall mining at different depths, coal seams, and geological conditions to establish the relative

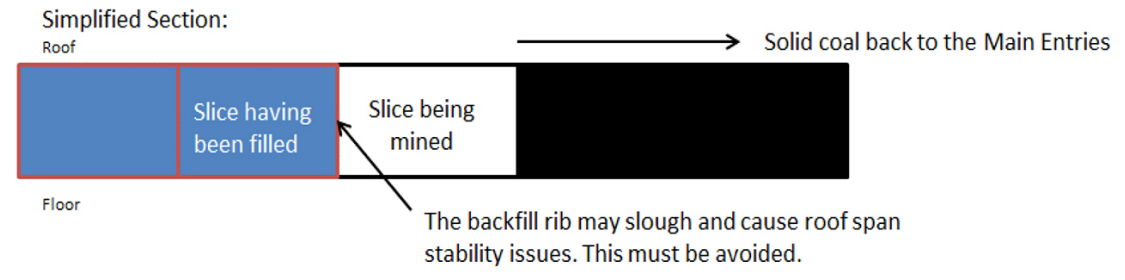

Figure 11-The need for adequate cohesion for the backfill to be free-standing 
cost-effectiveness of the methods. The concept study would need to include the leaving of web pillars between slots and the combination of web pillars and uncemented backfill (where backfilling to the roof is far less critical).

(3) SHURM should be the safest mining method because personnel are not working on the advancing face, which is typically the most hazardous work area.

(4) SHURM would seem, at this stage, to be able to recover more of the coal (or other soft-rock material such as trona or halite) than longwalling at depth unless backfilling is also incorporated with the longwalling. This is mainly because not all of a coal deposit at depth can be effectively mined using longwalling because of geological features. To be effective, a longwall panel needs to be at least $150 \mathrm{~m}$ wide and about $1500 \mathrm{~m}$ long.

(5) The method is environmentally friendly because the preferred use of backfill will reduce or eliminate any adverse groundwater and surface effects.

\section{References}

AfRISAm. Not dated. Slagment. https://www.afrisam.co.za/products-services/cement/ slagment

Blight, G.E. and SPEARInG, A.J.S. 1996. The properties of cemented silicate backfill for use in narrow, hard-rock, tabular mines. Journal of the South African Institute of Mining and Metallurgy, vol. 96, no. 1. http://saimm.org.za/Journal/ v096n01p017.pdf

Buddery, P. and Hill, D. 2004. Extraction panel and pillar design guidelines for high production underground auger mining in Australian conditions. Project Report C11041. Australian Coal Association, Brisbane.

Caterpillar. 2014. Performance Handbook Edition 44. Peoria, IL. 2020. Novel coal mining method. Provisional patent 202010057874.6.
MA, L., Jin, Z., Liu, W., Zhang, D., and Zhang, Y. 2019. Wongawilli roadway backfilling coal mining method-A case study in Wangtaipu coal mine. International Journal of Oil, Gas and Coal Technology, vol. 20. pp. 342-359.

Mo, S., Zhang, C., Canbulat, I., and Hagan, P. 2016. A review of highwall mining experience and practice. Proceedings of the Coal Operators Conference, University of Wollongong, New South Wales, Australia.

PBE Technologies. 2017. Underground mining system for reduced costs, improved efficiencies, higher productivity and a safer working environment through penetrated block extraction. Patent application 2017202727. Brisbane, Queensland.

Shen, B., Duncan Fama, M.E., Boland, J.H., Adhikary, D.P., and Maconochie, A.P. 2000 Monitoring and stability assessment at South Blackwater Mine of a punch longwall roadway developed using highwall mining technology. Research Project Report C9007. Australian Coal Association, Brisbane.

Smart, R.M., Spearing, A.J.S. and Harrison, A.T. 1993. The use of silicate backfill in South African gold mines. Proceedings of Minefill '93. Southern African Institute of Mining and Metallurgy, Johannesburg.

Smith, K. and KNIGHT Hawk CoAl LLC. Personal Communication. June 2020.

VolKwein, J.C., Mucho, T.P., and BнAтT, S.K. 1995. Safety, technological, and productivity potentials of highwall mining. U.S. Department. of Labor, MSHA, Holmes Safety Association Bulletin, January. pp. 4-11.

WANG, S. and MA, L. 2017. Characteristics and control of mining induced fractures under continuous excavation and continuous backfilling in longwall mining. Energies, vol. 12, 4604. doi: 110.3390/en12234604

Yu, Y., MA, L., and ZHANG, D. 2020. Characteristics of roof ground subsidence while applying a continuous excavation continuous backfill method in longwall mining. Energies, vol. 13, no. 1. 95.14. https://doi.org/10.3390/en13010095

ZHANG, J.X., ZHou, Y.J., AND HuAng, Y.L. 2012. Integrated technology of fully mechanized solid backfill mining. Journal of China Coal Society, vol. 11. pp. $10-13$.

Zhang, J.X., MiAo, X.X., and Guo, G.L. 2009. Development status of backfilling technology using raw waste in coal mining. Journal of Mining and Safety Engineering, vol. 26. pp. 395-401.

ZIPF, K. 2005. Ground control design for highwall mining. Proceedings of the SME Annual General Meeting, February. Society for Mining, Metallurgy \& Exploration, Littleton, CO.

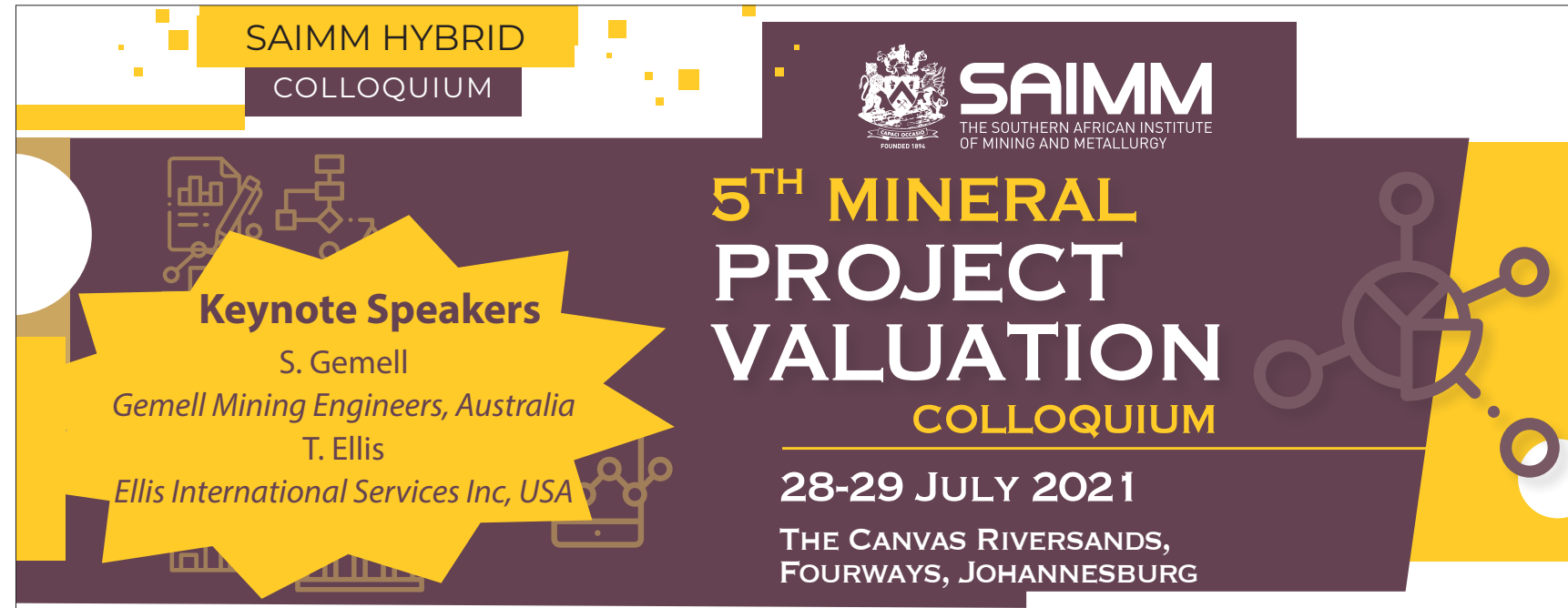

\section{BACKGROUND}

The SAIMM announces the $5^{\text {th }}$ Mineral Project Valuation Colloquium. This very successful Colloquium has been run in 2011, 2012, 2014 and 2017. The Colloquium will start with the basics for determining market values for mineral projects using the Income Approach (Discounted Cash Flows). The Colloquium will then progress to advanced discussions around shortcomings of the various current methods as well as new approaches. This colloquium will thus cover a broad selection of topics and should be of value for anyone in the mineral asset valuation (MAV) space. Whether you a mining engineer, project geologist or consultant, the lessons, presentations, and discussions will cater to all experience levels, from novice to highly experienced valuators. 